OPEN ACCESS

Edited by:

Ghulam Jeelani,

The University of Tokyo, Japan

Reviewed by:

Gildardo Rivera,

Instituto Politécnico Nacional (IPN),

Mexico

Emmanuel Oluwadare Balogun, Ahmadu Bello University, Nigeria

*Correspondence:

Maria de Nazaré Correia Soeiro soeiro@ioc.fiocruz.br

Specialty section: This article was submitted to Parasite and Host, a section of the journal

Frontiers in Cellular

and Infection Microbiology

Received: 15 October 2020 Accepted: 15 January 2021

Published: 04 March 2021

Citation:

Rocha-Hasler M, de Oliveira GM, da Gama AN, Fiuza LFdA, Fesser AF,

Cal M, Rocchetti R, Peres RB,

Guan XL, Kaiser M, Soeiro MdNC and

Mäser $P$ (2021) Combination With

Tomatidine Improves the

Potency of Posaconazole

Against Trypanosoma cruzi.

Front. Cell. Infect. Microbiol. 11:617917.

doi: 10.3389/fcimb.2021.617917

\section{Combination With Tomatidine Improves the Potency of Posaconazole Against Trypanosoma cruzi}

\author{
Marianne Rocha-Hasler ${ }^{1,2,3}$, Gabriel Melo de Oliveira ${ }^{1}$, Aline Nefertiti da Gama ${ }^{1}$, \\ Ludmila Ferreira de Almeida Fiuza ${ }^{1}$, Anna Frieda Fesser ${ }^{2,3}$, Monica Cal ${ }^{2,3}$, \\ Romina Rocchetti ${ }^{2,3}$, Raiza Brandão Peres ${ }^{1}$, Xue Li Guan ${ }^{4}$, Marcel Kaiser ${ }^{2,3}$, \\ Maria de Nazaré Correia Soeiro ${ }^{1 *}$ and Pascal Mäser ${ }^{2,3}$ \\ ${ }^{1}$ Laboratório de Biologia Celular, Instituto Oswaldo Cruz (IOC/Fiocruz), Pavilhão Cardoso Fontes, Rio de Janeiro, Brazil, \\ 2 Parasite Chemotherapy Unit, Swiss Tropical and Public Health Institute, Medical Parasitology and Infection Biology, Basel, \\ Switzerland, ${ }^{3}$ University of Basel, Basel, Switzerland, 4 Systems Biology of Lipid Metabolism in Human Health and Diseases \\ Laboratory, Lee Kong Chian School of Medicine, Singapore, Singapore
}

Azoles such as posaconazole (Posa) are highly potent against Trypanosoma cruzi. However, when tested in chronic Chagas disease patients, a high rate of relapse after Posa treatment was observed. It appears that inhibition of T. cruzi cytochrome CYP51, the target of azoles, does not deliver sterile cure in monotherapy. Looking for suitable combination partners of azoles, we have selected a set of inhibitors of sterol and sphingolipid biosynthetic enzymes. A small-scale phenotypic screening was conducted in vitro against the proliferative forms of $T$. cruzi, extracellular epimastigotes and intracellular amastigotes. Against the intracellular, clinically relevant forms, four out of 15 tested compounds presented higher or equal activity as benznidazole (Bz), with $\mathrm{EC}_{50}$ values $\leq 2.2 \mu \mathrm{M}$. Ro48-8071, an inhibitor of lanosterol synthase (ERG7), and the steroidal alkaloid tomatidine $(\mathrm{TH})$, an inhibitor of C-24 sterol methyltransferase (ERG6), exhibited the highest potency and selectivity indices (SI $=12$ and 115, respectively). Both were directed to combinatory assays using fixed-ratio protocols with Posa, Bz, and fexinidazole. The combination of $\mathrm{TH}$ with Posa displayed a synergistic profile against amastigotes, with a mean $\Sigma \mathrm{FICl}$ value of 0.2. In vivo assays using an acute mouse model of $T$. cruzi infection demonstrated lack of antiparasitic activity of $\mathrm{TH}$ alone in doses ranging from 0.5 to $5 \mathrm{mg} /$ $\mathrm{kg}$. As observed in vitro, the best combo proportion in vivo was the ratio $3 \mathrm{TH}: 1 \mathrm{Posa}$. The combination of Posa at $1.25 \mathrm{mpk}$ plus TH at $3.75 \mathrm{mpk}$ displayed suppression of peak parasitemia of $80 \%$ and a survival rate of $60 \%$ in the acute infection model, as compared to $20 \%$ survival for Posa at 1.25 mpk alone and $40 \%$ for Posa at $10 \mathrm{mpk}$ alone. These initial results indicate a potential for the combination of posaconazole with tomatidine against $T$. cruzi.

Keywords: Chagas disease, tomatidine hydrochloride, drug combination, T. cruzi, lipid biosynthesis inhibitor 


\section{INTRODUCTION}

Chagas disease (CD), a vector-borne anthropozoonosis endemic in the American continent, is caused by the protozoan parasite Trypanosoma cruzi (Chagas, 1909). The triatomine vector of CD is spread from the southern United States to the south of Argentina. Due to increasing global migration, CD has spread to other continents through a diversity of other transmission routes such as blood transfusion, organ transplantation, and mother-to-child (Gascon et al., 2010; Pérez-Molina and Molina, 2018). Also, oral transmission due to beverages contaminated with the feces or with infected triatomines currently represents a serious challenge in many endemic areas such as Brazil (Coura et al., 2014; Dias, 2017). This neglected disease presents a short acute phase with patent parasitemia, which is usually asymptomatic or oligosymptomatic with "flu-like" symptoms (Prata, 2001; Rassi et al., 2010). After six to nine weeks, parasite proliferation is controlled due to a competent immune response, and infected individuals enter a second stage, the chronic phase, with most of them remaining in an indeterminate form. However, after years or even decades, about $30 \%$ of the patients in the chronic phase develop progressive cardiac or gastrointestinal injuries (Ribeiro et al., 2012; Malik et al., 2015).

The front-line drugs for $\mathrm{CD}$ are two nitroderivatives, benznidazole $(\mathrm{Bz})$ and nifurtimox. Both are far from ideal, with the occurrence of naturally resistant strains, lack of efficacy in the later chronic phase, and severe side effects that led to $10-30 \%$ therapy withdrawals (Molina et al., 2015). These limitations highlight an urgent need for novel, potent, and safer drugs for $\mathrm{CD}$, and many strategies have been followed, including drug repurposing and drug combinations (Coura, 2009; Miranda and Sayé, 2019).

Drug combination may tackle more than one target simultaneously, allowing reduced doses, costs, time of drug administration, and reducing the risk of parasite drug resistance, providing increased efficacy and selectivity (Sun et al., 2016). These approaches have been largely explored in experimental models of Chagas disease (Batista et al., 2011; Diniz et al., 2013) as well as in clinical trials with chronic chagasic patients (Morillo et al., 2017).

Regarding drug repurposing, the identification of targets in $T$. cruzi shared by other pathogens fueled several in vitro and in vivo assays (Sales Junior et al., 2017). These piggy-back studies comprised fungal ergosterol biosynthesis inhibitors (EBIs) such as posaconazole (Posa) and E1224, the prodrug of ravuconazole (Sales Junior et al., 2017; Urbina, 2018), as well as a set of more specific inhibitors of the protozoan CYP51 orthologs, for instance VNI [(R)-N-(1-(2,4-dichlorophenyl)-2-(1H-imidazol-1-yl)ethyl)-4-(5phenyl-1,3,4-oxadiazol-2-yl)benzamide)] and derivatives (Guedesda-Silva et al., 2015). Unfortunately, both Posa and E1224 failed in clinical trials for $\mathrm{CD}$, and many possibilities were raised regarding the lack of translation from the preclinical to clinical outcomes (Morillo et al., 2017; Chatelain and Ioset, 2018; Torrico et al., 2018).

A possible explanation for the disappointing outcome of the clinical trials with azole-type CYP51 inhibitors is, that these molecules fail to kill every single parasite, i.e., they have high $\mathrm{EC}_{99}$ values. This notion is supported by in vivo (Francisco et al., 2015) and in vitro (Moraes et al., 2014; Cal et al., 2016; Fesser et al., 2020) models of pharmacodynamics. Nevertheless, azole- type CYP51 inhibitors have nanomolar $\mathrm{EC}_{50}$ values against $T$. cruzi and a high selectivity index, and they are well tolerated by the treated patients (Morillo et al., 2017). As a strategy to overcome the limitation of CYP51 inhibitors, we have proposed to combine them with a partner drug that either acts in the same pathway, sterol biosynthesis, or that inhibits a functionally linked pathway, sphingolipid synthesis (Fügi et al., 2015). Both rationales are supported by genetic interaction data from yeast (Eisenkolb et al., 2002; Guan et al., 2009; Fügi et al., 2015). Sphingolipids are a major class of lipids and ubiquitous constituents of eukaryotic membranes, playing also a role as bioactive signaling molecules involved in the regulation of cell growth, differentiation, senescence, and death (Pruett et al., 2008), as well as in virulence and survival of pathogens upon interaction with the host, including T. cruzi (Goldston et al., 2012; Guan and Mäser, 2017).

In the present work, we have assembled a panel of fifteen drugs and experimental compounds that interfere either with sterol synthesis or with sphingolipid metabolism. The compounds, their target enzymes, and their medical use (if any) are described in Table 1. All compounds were phenotypically assayed against the multiplicative forms of $T$. cruzi. Identified hit compounds were further combined with Posa and reference drugs in in vitro and in vivo models of parasite experimental infection.

\section{MATERIALS AND METHODS}

\section{Compounds}

Amitryptiline (hydrochloride), FTY720, FTY720 phosphate, AMPdeoxynojirimicin, D609 (potassium salt), fumonisin B1, myriocin, Ro48-8071, TMP-153, GW4869 (hydrochloride hydrate), PDMP (hydrochloride), tomatidine hydrochloride $(\mathrm{TH})$ were purchased from Cayman chemicals and bezafibrate, quinuclidine hydrochloride, 3-aminoquinuclidine dihydrochloride, and posaconazole (Posa) were from Sigma-Aldrich Switzerland. Fexinidazole (Fexi) was received from DNDi and benznidazole (Bz) was purchased from Laboratório Farmacêutico do Estado de Pernambuco (Brazil). For in vitro tests, stock solutions of each compound were prepared in DMSO, never exceeding 0.6\% DMSO as final concentration, which does not induce cellular damages to mammalian cells and parasites. For in vivo, Bz, Posa, and TH were prepared for oral (p.o., $100 \mu \mathrm{l}$ ) administration in extemporaneous solutions. For in vivo drug vehicles, $\mathrm{Bz}$ was diluted in distilled water with 3\% Tween 80 (Sigma-Aldrich, Belgium), Posa and TH in aqueous solution of $0.5 \%$ carboxymethylcellulose (SigmaAldrich, Belgium).

\section{Mammalian Cells and Parasites for In Vitro Assays}

L6 cells derived from rat skeletal myoblast (ATCC CRL-1458) were used as host cells for T. cruzi using trypomastigotes of Tulahuen C2C4 strain (DTU VI) expressing the $\beta$-galactosidase gene (LacZ) (Buckner et al., 1996). The cultures were sustained in RPMI-1640 supplemented with $10 \%$ inactivated fetal bovine serum (FBS) and $2 \mu \mathrm{M}$ L-glutamine at $5 \% \mathrm{CO}_{2}$ and $37^{\circ} \mathrm{C}$. Epimastigote T. cruzi (STIB 980 strain, DTU TcI) were 
TABLE 1 | Compounds used in this study, their mode of action, and medical use.

Chemical structure

Target/MoA

Oxydative stress after activation by

nitroreductase

[31593]

Fexinidazole

[68792]

\section{Lipid signaling}

Bezafibrate

[39042]

D609

[4234241]<smiles>O=C(Cn1ccnc1[N+](=O)[O-])NCc1ccccc1</smiles><smiles>CSc1ccc(OCc2ncc([N+](=O)[O-])n2C)cc1</smiles><smiles>CCc1ccc(C(=O)NCCc2ccc(OC(C)(C)C(=O)O)cc2)cc1</smiles>

FTY720

[107969]

FTY720-P

[9908268]

\section{Sterol synthesis}

Quinuclidine

[7527]

3-Amino

quinuclidine

[123238]

Ro48-8071

[1949]

Posaconazole [468595]<smiles>S=C(S)OC1CC2CC1C1CCCC21</smiles><smiles>CCCCCCCCc1ccc(CCC(N)(CO)CO)cc1</smiles>

Oxydative stress after activation by nitroreductase I

Peroxisome proliferator-activated receptor $\alpha$ agonist
Indication/Use

Chagas disease

Human African trypanosomiasis

Hyperlipidemia
Phosphatidylcholine-specific phospholipase Experimental C

Parent molecule (Fingolimod) of FTY720-P

Sphingosine-1-phosphate-receptors

see above

Multiple sklerosis, immunomodulatory

Experimental

Derivatives inhibit squalene synthase (Erg9)

Derivatives inhibit squalene synthase (Erg9)

Oxidosqualene cyclase

(Erg7)

Lanosterol 14- $\alpha$ demethylase (Erg11)
Antifungal

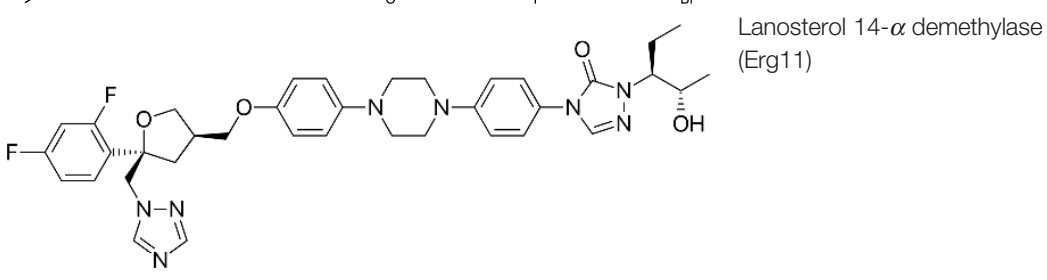

(Continued) 
TABLE 1 | Continued

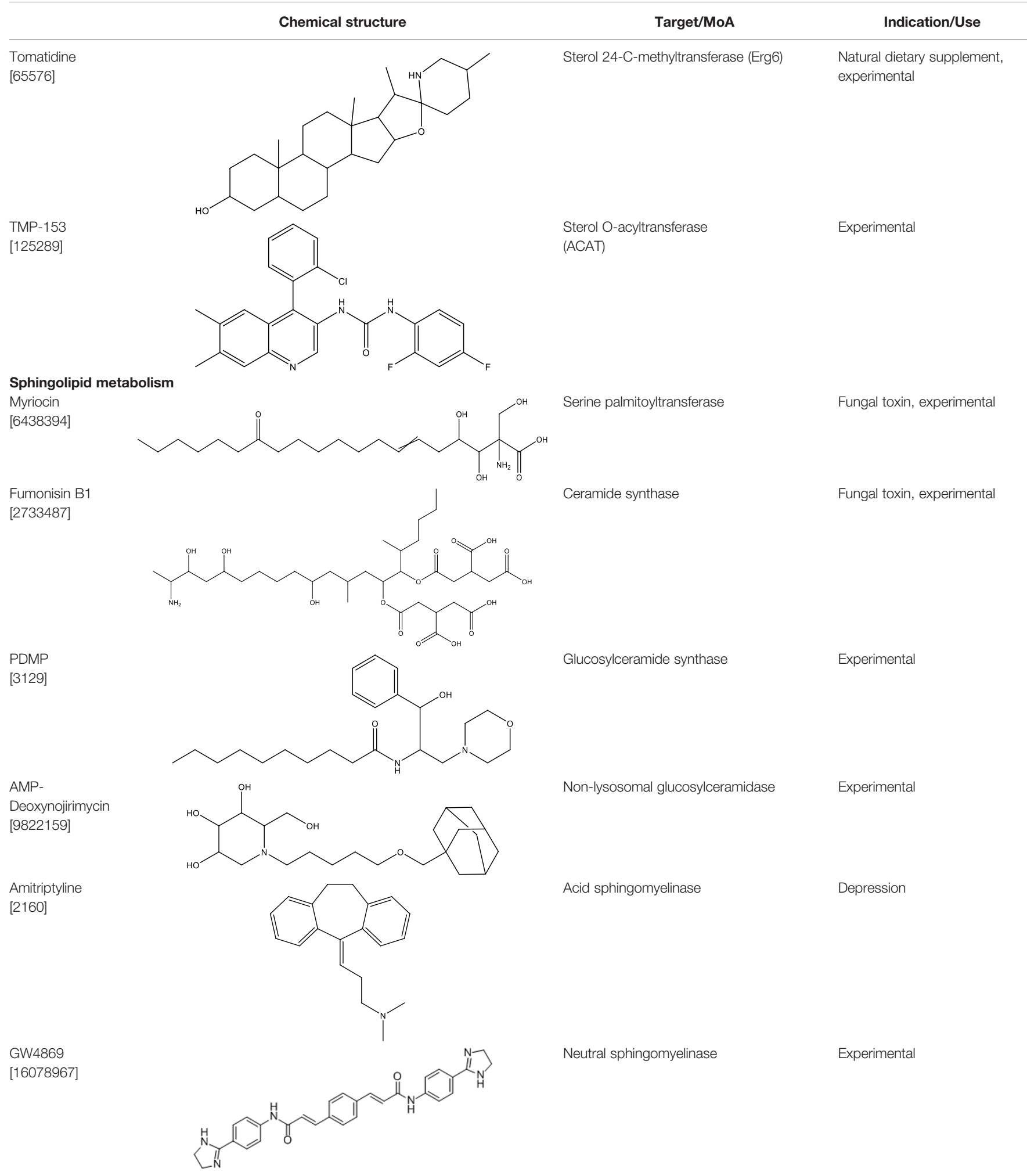

Numbers in brackets are PubChem compound ID numbers (pubchem.ncbi.nlm.nih.gov; Kim et al., 2021). 
cultivated at $28^{\circ} \mathrm{C}$ in liver infusion tryptose (LIT) medium supplemented with hemin $(2 \mu \mathrm{g} / \mathrm{ml})$ and $10 \%$ FBS and were used in log phase of growth. Bloodstream trypomastigotes ( $Y$ strain, DTU II) were isolated from Swiss Webster mice infected at the peak of parasitemia $\left(\geq 2.5 \times 10^{6} / \mathrm{ml}\right)$, as reported (Meirelles et al., 1986).

\section{Activity on T. cruzi Epimastigotes}

Epimastigotes $\left(10^{7}\right.$ parasites $\left./ \mathrm{ml}\right)$ were incubated for $72 \mathrm{~h}$ at $28^{\circ} \mathrm{C}$ with serially diluted compound concentrations (eleven 1:3 dilutions) in supplemented LIT medium. Parasite viability and motility were evaluated by direct observation by light microscopy and fluorometric assays performed with resazurin $(12.5 \mathrm{mg}$ resazurin dissolved in $100 \mathrm{ml}$ distilled water). After 2-4 h of incubation with resazurin solution, plates were read in Spectramax Gemini XS microplate fluorometer (Molecular Devices Cooperation, USA) using wavelengths of $536 \mathrm{~nm}$ (excitation) and $588 \mathrm{~nm}$ (emission) (Räz et al., 1997). Growth was expressed as percentage of the values of solvent-treated controls. The graphics program Softmax Pro (Molecular Devices) was used to construct dose-response curves and calculate $\mathrm{EC}_{50}$ (half maximal inhibitory concentration) values. Bz was used as reference drug.

\section{Activity on $T$. cruzi Intracellular Amastigotes}

Rat skeletal myoblasts (L6 cell lines) were seeded in 96-well plates ( $10^{4}$ cells/well) in $100 \mu \mathrm{l}$ RPMI 1640 medium supplemented with $10 \%$ fetal bovine serum (FBS) and $2 \mathrm{mM} \mathrm{L}$-glutamine. The medium was removed after $24 \mathrm{~h}$ incubation and replaced by $100 \mu \mathrm{l}$ of fresh medium containing $10^{5}$ LacZ trypomastigotes (Tulahuen DTU VI). After $48 \mathrm{~h}$, the medium was again removed and replaced with or without a serial of compound concentrations (eleven three-fold dilution steps). After $96 \mathrm{~h}$ of compound exposure, CPRG/Nonidet $(50 \mu \mathrm{l})$ substrate was added and the reading performed after 2-6 h at $540 \mathrm{~nm}$ in Versamax microplate reader (Molecular Devices Cooperation, USA). Growth was expressed as percentage of the values of solvent-treated controls. The graphics program Softmax Pro (Molecular Devices) was used to construct dose-response curves and calculate $\mathrm{EC}_{50}$ values. $\mathrm{Bz}$ was used as reference drug.

\section{Cytotoxicity Against L6 Cells}

Rat skeletal myoblasts (L6 cell lines) were seeded in 96-well plates $\left(4 \times 10^{4}\right.$ cells/well $)$ in $100 \mu \mathrm{l}$ RPM 1640 medium supplemented with $10 \%$ fetal bovine serum (FBS) and $2 \mathrm{mM}$ L-glutamine. After $24 \mathrm{~h}$ incubation the medium was replaced with $100 \mu \mathrm{l}$ of fresh medium with or without a serial dilution of compound concentrations (eleven three-fold dilution steps). After $72 \mathrm{~h}$ of compound exposure, fluorescent dye resazurin ( $10 \mu \mathrm{l}, 12.5 \mathrm{mg}$ resazurin dissolved in $100 \mathrm{ml}$ water) was added for $2 \mathrm{~h}$ and the readings performed at Spectramax Gemini XS microplate fluorometer (Molecular Devices Cooperation, USA), with excitation wavelength of $536 \mathrm{~nm}$ and an emission wavelength of $588 \mathrm{~nm}$. Growth was expressed as percentage of the values of solvent-treated controls. The graphics program Softmax Pro (Molecular Devices) was used to construct doseresponse curves and calculate $\mathrm{EC}_{50}$ values. Podophyllotoxin (a microtubule destabilizing agent) was used as positive control.

\section{Drug Combination}

In vitro drug interactions on L6 cell cultures infected with Lac-Z T. cruzi using TH or Ro48-8071 combined to Bz, Posa or Fexi were performed at 1:3, 1:1, and 3:1 fixed-ratios (Fivelman et al., 2004) according to the same protocol as described above. Fractional inhibitory concentration indexes (FICI) and the sum of FICIs ( $\sum$ FICI) were calculated as follows: FICI values $=\mathrm{EC}_{50}$ or $\mathrm{EC}_{90}$ of the combination/ $\mathrm{EC}_{50}$ or $\mathrm{EC}_{90}$ of each compound alone. An overall $\Sigma$ FICI was then determined and used to classify the nature of each interaction (Odds, 2003). $\sum$ FICI $\leq 0.5=$ synergism; $0.5<\sum F I C I \leq$ $4.0=$ additive (no interaction); $\sum F I C I>4.0=$ antagonism.

Isobolograms were built by plotting the FICI of compound 1 against the FICI of compound 2 .

\section{Animals}

Male Swiss Webster mice (18-23 g) were obtained from the Instituto de Ciência e Tecnologia em Biomodelos (ICTB/ Fiocruz) (Rio de Janeiro, Rio de Janeiro, Brazil). Five mice were housed per cage, kept in a conventional room at $20-24^{\circ} \mathrm{C}$ under $12 \mathrm{~h} / 12 \mathrm{~h}$ light/dark cycle. Sterilized water and chow were provided ad libitum. The animals were acclimated for 7 days before being used in the different assays. All procedures were done following Biosafety Guidelines in compliance with the Fiocruz and all animal procedure approved by the Committee of Ethics for the Use of Animals (CEUA L-38/17).

\section{Mouse Infection and Efficacy Studies}

Male mice ( $\mathrm{n}=5$ per group) were infected i.p. with $10^{4}$ bloodstream trypomastigotes of $T$. cruzi (Y strain). Only mice with positive parasitemia at day 5 post infection (dpi) were included in the studies. T. cruzi-infected mice were treated (p.o.) for ten consecutive days, from 5 to $14 \mathrm{dpi}$, with Posa (10 and $1.25 \mathrm{mg} / \mathrm{kg}$ body weight (mpk) corresponding to optimal and suboptimal doses of Posa for parasitemia suppression, respectively), TH (5-0.5 mpk) and combos of Posa plus TH, using the suboptimal dose of Posa (1.25 $\mathrm{mpk}$ ) in different proportions, nearby those with best in vitro outcomes as follows: Posa $1.25 \mathrm{mpk}+$ TH $5 \mathrm{mpk}$ (ratio 1:4), Posa $1.25 \mathrm{mpk}+$ TH $3.75 \mathrm{mpk}$ (ratio 1:3) and Posa $1.25 \mathrm{mpk}+$ TH $0.5 \mathrm{mpk}$ (ratio 2.5:1)). Uninfected and T. cruzi-infected mice treated only with vehicle (aqueous solution of $0.5 \%$ carboxymethylcellulose) were agematched and housed under identical conditions and used as controls (Simões-Silva et al., 2017). All compound formulations were freshly prepared before every administration.

\section{Parasitemia, Mortality Rates, and Endpoint} All animals were individually checked for circulating blood parasitemia by counting the number of parasites in $5 \mu \mathrm{l}$ of blood taken from the tail vein and investigated under the microscope (Brener, 1962). Parasitemia was checked till $30 \mathrm{dpi}$, while mortality was checked daily up to 30 days after the administration of the last dose. Mortality was given as percentage of cumulative mortality (CM) (Simões-Silva et al., 2017).

\section{Statistical Analysis}

All experiments were performed in triplicate in three independent experimental sets. The citotoxicity and antitrypanosomal activity were analyzed by ANOVA/Dunnet test using GraphPad Prism 
5.01 software. $P$ values of 0.05 or lower were assumed as significant.

\section{RESULTS}

The in vitro activity of the fifteen compounds (Table 1) was assessed on the multiplicative forms of T. cruzi: epimastigotes (strain STIB 980) and intracellular amastigotes (Tulahuen C2C4 strain expressing the $\beta$-galactosidase gene LacZ) (Table 2). In parallel, the cytotoxicity of the compounds was evaluated on mammalian host cells (Table 2). Against T. cuzi epimastigotes, two compounds (FTY720 and Ro48-8071) were promising, displaying similar potency as $\mathrm{Bz}(7.55,11.6$ and $13.9 \mu \mathrm{M}$, respectively; both of which were not significantly different to $\mathrm{Bz}$, with $p$ values $>0.05$ in comparison to $\mathrm{Bz}$ ), and showing about 2.5-8-fold lower $\mathrm{EC}_{90}$ values than the reference drug (both with $p<0.05$ ) (Table 2). Against the intracellular amastigotes, four compounds (FTY720, RO48-8071, tomatidine hydrochloride (TH) and TMP-153) displayed $\mathrm{EC}_{50}$ values $\leq 1 \mu \mathrm{M}$, lower than $\mathrm{Bz}(2.2 \mu \mathrm{M})$ (the four compounds presenting $p<0.05$ in comparison to $\mathrm{Bz}$ ) (Table 2). Most of the tested compounds showed quite relevant toxicity towards mammalian host cells, leading to low selectivity indices (SIs), except for Ro48-8071 and TH, which presented promising SIs of 12 and 115, respectively (Table 2).

Based on their high activity against intracellular amastigote $T$. cruzi and good selectivity towards the mammalian host cells, Ro48-8071 and tomatidine were moved to in vitro combination assays with the reference drug for CD $(\mathrm{Bz})$ and two others that displayed efficacy in in vitro and in vivo assays of T. cruzi experimental infection: the imidazole CYP51 inhibitor Posa and the nitroimidazole Fexinidazole (Fexi) (Table 3). Of the six combinations tested, only that between TH and Posa had a synergistic profile with mean $\Sigma$ FICI values below 0.5, based on their $\mathrm{EC}_{50}$ (Table 3, Figure 1). These results encouraged us to follow up with in vivo studies. Posa or TH did not show any signs of toxicity when administered to female mice p.o. up to $200 \mathrm{mpk}$ (data not shown).

Before moving to co-administration schemes, TH and Posa alone were administered in mouse models of acute T. cruzi infection (Figure 2). Posa at $10 \mathrm{mpk}$ suppressed parasitemia on the peak ( $8 \mathrm{dpi}$ ), providing $40 \%$ survival of mice, while all vehicletreated mice died until the endpoint (Figure 2). A suboptimal dose of Posa (1.25 mpk) decreased the parasitemia peak (about $80 \%$ ), but only provided a mild protection against mortality $(20 \%$ of animal survival) (Figure 2). On the other hand, all tested doses of $\mathrm{TH}$ (up to $5 \mathrm{mpk}$ ) alone resulted in a maximum reduction of only $28 \%$ in blood parasitemia on the peak and were unable to protect against the mortality induced by the infection since all animals died by 20 dpi (Figure 2).

The co-administration of $\mathrm{TH}$ (variable doses from 0.5 to 5 mpk) plus Posa at the suboptimal dose of $1.25 \mathrm{mpk}$ led to a parasitemia drop ranging from 60 to $80 \%$, and cumulative death ranging from 40 to $100 \%$ (Figure 3). The best effect as evaluated by the concomitant reduction in peak parasitemia (80\%) and increased animal survival $(60 \%)$ was achieved with the combo Posa $1.25 \mathrm{mpk}+$ TH $3.75 \mathrm{mpk}$ (ratio 1:3) (Figure 3), which corroborated the best in vitro ratio of combination (Table 3 ).

\section{DISCUSSION}

Drug repurposing and drug combination are pre-clinical strategies used in experimental pharmacology to tackle many diseases,

TABLE 2 | Activity ( $\mathrm{EC}_{50}$ and $\mathrm{EC}_{90}, \mu \mathrm{M}, \mathrm{n}=3$ ) and selectivity of lipid biosynthesis inhibitors on Trypanosoma cruzi epimastigotes (STIB 980 strain) and intracellular amastigotes (Tulahuen strain in rat L6 myoblasts).

\begin{tabular}{|c|c|c|c|c|c|c|}
\hline \multirow[b]{2}{*}{ Compound } & \multicolumn{2}{|c|}{ Epimastigotes (mean $\pm S D)(\mu M)$} & \multicolumn{2}{|c|}{ Amastigotes (mean $\pm S D)(\mu M)$} & \multicolumn{2}{|l|}{ L6 cells (mean $\pm S D)(\mu M)$} \\
\hline & $\mathrm{EC}_{50}$ & $\mathrm{EC}_{90}$ & $\mathrm{EC}_{50}$ & $\mathrm{EC}_{90}$ & $\mathrm{EC}_{50}$ & $\left.S\right|^{\mathrm{a}}$ \\
\hline Benznidazole & $13.9 \pm 2.2$ & $101 \pm 18$ & $2.22 \pm 0.98$ & $6.61 \pm 2.5$ & $>384$ & $>172$ \\
\hline Bezafibrate & $>276$ & $>276$ & $132.3 \pm 38.6$ & $226 \pm 65$ & $>276$ & $>2.1$ \\
\hline $\begin{array}{l}\text { D609 } \\
\text { (potassium salt) }\end{array}$ & $154 \pm 32$ & $>375$ & $99.4 \pm 17.6$ & $198 \pm 32$ & $247 \pm 20$ & 2.5 \\
\hline FTY720 & $7.55 \pm 0.4$ & $11.6 \pm 0.3$ & $0.81 \pm 0.5$ & $1.84 \pm 1.3$ & $0.39 \pm 0.1$ & 0.5 \\
\hline FTY720 Phosphate & $>258$ & $>258$ & $93.8 \pm 3.3$ & $168 \pm 25$ & $127 \pm 22$ & 1.4 \\
\hline Quinuclidine hydrochloride & $>677$ & $>677$ & $478 \pm 174$ & $>677$ & $>677$ & $>1.4$ \\
\hline $\begin{array}{l}\text { 3-Amino } \\
\text { quinuclidine dihydrochloride }\end{array}$ & $>502$ & $>502$ & $268 \pm 10$ & $485 \pm 28$ & $>502$ & $>1.8$ \\
\hline Ro48-8071 & $11.6 \pm 6.1$ & $29.4 \pm 16.2$ & $0.47 \pm 0.09$ & $2.5 \pm 1.9$ & $5.7 \pm 2.4$ & 12 \\
\hline Posaconazole & $>14.2$ & $>14.2$ & $0.002 \pm 0.001$ & $0.016 \pm 0.005$ & $>1.42$ & $>700$ \\
\hline Tomatidine (hydrochloride) & $192 \pm 8.1$ & $>221$ & $0.78 \pm 0.2$ & $1.8 \pm 0.2$ & $89.5 \pm 26.7$ & 115 \\
\hline TMP-153 & $106 \pm 27$ & $>228$ & $0.09 \pm 0.04$ & $3.9 \pm 2.1$ & $0.12 \pm 0.03$ & 1.4 \\
\hline Myriocin & $>249$ & $>249$ & $130 \pm 34$ & $231 \pm 25$ & $>249$ & $>1.9$ \\
\hline Fumonisin B1 & $>92$ & $>92$ & $50.8 \pm 5.7$ & $84 \pm 9.1$ & $>92$ & $>1.8$ \\
\hline PDMP (hydrochloride) & $47.9 \pm 9.4$ & $88.7 \pm 18$ & $12.5 \pm 2.9$ & $24.6 \pm 9$ & $33.5 \pm 3.1$ & 2.7 \\
\hline $\begin{array}{l}\text { AMP-Deoxy } \\
\text { nojirimycin }\end{array}$ & $158 \pm 5.9$ & $237 \pm 2$ & $34.8 \pm 15.1$ & $66.6 \pm 15.4$ & $40.4 \pm 10.9$ & 1.2 \\
\hline Amitriptyline (hydrochloride) & $59.9 \pm 5.4$ & $96.8 \pm 3.3$ & $12.2 \pm 3.6$ & $20.9 \pm 3$ & $17.2 \pm 1.2$ & 1.4 \\
\hline GW4869 (hydrochloride hydrate) & $>173$ & $>173$ & $106 \pm 44$ & $>173$ & $>173$ & $>1.7$ \\
\hline
\end{tabular}

${ }^{a}$ Selectivity Index based on the $\mathrm{EC}_{50}$ and $\mathrm{EC}_{50}$ on intracellular amastigotes and the mammalian cells, respectively. 
TABLE 3 | Sum of the mean fractional inhibitory concentration indices ( $\Sigma \mathrm{FICl})$ of the combinations between Ro48-8071 or tomatidine hydrochloride and benznidazole, posaconazole, or fexinidazole in different fixed ratio proportions (1:3, 1:1, and 3:1; the first number corresponds to the standard drug) against $T$. cruzi intracellular amastigotes (strain Tulahuen in L6 cell lines).

\begin{tabular}{|c|c|c|c|c|c|c|c|c|c|c|c|c|}
\hline \multirow[t]{3}{*}{ Combos Mean $\Sigma$ FICls } & \multicolumn{4}{|c|}{ Benznidazole } & \multicolumn{4}{|c|}{ Posaconazole } & \multicolumn{4}{|c|}{ Fexinidazole } \\
\hline & \multicolumn{2}{|c|}{ Ro48-8071 } & \multicolumn{2}{|c|}{ Tomatidine hydrochloride } & \multicolumn{2}{|c|}{ Ro48-8071 } & \multicolumn{2}{|c|}{ Tomatidine hydrochloride } & \multicolumn{2}{|c|}{ Ro48-8071 } & \multicolumn{2}{|c|}{ Tomatidine hydrochloride } \\
\hline & $\mathrm{EC}_{50}$ & $\mathrm{EC}_{90}$ & $\mathrm{EC}_{50}$ & $\mathrm{EC}_{90}$ & $\mathrm{EC}_{50}$ & $\mathrm{EC}_{90}$ & $\mathrm{EC}_{50}$ & $\mathrm{EC}_{90}$ & $\mathrm{EC}_{50}$ & $\mathrm{EC}_{90}$ & $E_{50}$ & $\mathrm{EC}_{90}$ \\
\hline $1: 3$ & 1.8 & 1.5 & 0.7 & 1.0 & 1.1 & 0.8 & 0.1 & 0.4 & 1.4 & 1.2 & 1.4 & 0.9 \\
\hline $1: 1$ & 4.0 & 3.3 & 1.1 & 1.1 & 1.6 & 1.7 & 0.2 & 0.7 & 3.6 & 3.1 & 1.1 & 0.9 \\
\hline $3: 1$ & 4.0 & 5.0 & 1.7 & 1.3 & 4.4 & 3.5 & 0.3 & 0.4 & 5.5 & 5.0 & 1.7 & 1.7 \\
\hline
\end{tabular}

$\Sigma \mathrm{FlCl} \leq 0.5$ synergism; $0.5<\Sigma \mathrm{FlCl} \leq 4$ additive (no interaction); $\Sigma \mathrm{FICl}>4$ antagonism.

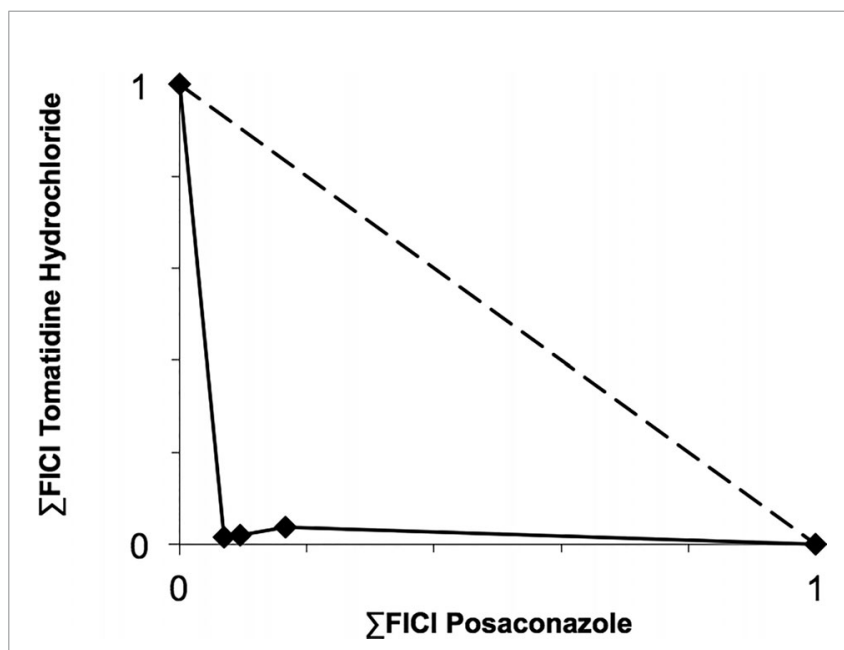

FIGURE 1 | Isobologram showing the sum of the fractional inhibitory concentration indexes $\left(\sum \mathrm{FICl}\right)$ of tomatidine hydrochloride and posaconazole, demonstrating the synergistic interaction of the combination in different fixed ratio proportions $(1: 3,1: 1$, and $3: 1)$ against $T$. cruzi intracellular amastigotes (strain Tulahuen in L6 cells). $\Sigma \mathrm{FICl} \leq 0.5=$ synergism; $0.5<\sum \mathrm{FIC} \leq 4.0=$ additive (no interaction); $\Sigma \mathrm{FICl}>4.0=$ antagonism

reaching quite effective results when applied to clinical trials and off-label use (Sbaraglini et al., 2016). Successful examples from neglected tropical diseases include the repositioning of nifurtimox administered in combination with eflornithine for Human African trypanosomiasis (Priotto et al., 2007), the association of miltefosine and paromomycin, and sodium stibogluconate plus paromomycin, for visceral leishmaniasis (Atia et al., 2015; Rahman et al., 2017; Alves et al., 2018). Regarding Chagas disease, fungicidal inhibitors of CYP51 enzymes have been assayed in clinical trials (e.g., Posa and E1224 in association with Bz), but unfortunately had high rates of therapeutic failure (Morillo et al., 2017; Torrico et al., 2018). On the other hand, the BENEFIT trial demonstrated that, although effective to reduce parasite load in chronic chagasic patients, $\mathrm{Bz}$ did not impair the progression of cardiac damages, reinforcing the need to search for new therapeutic alternatives for CD (Rassi et al., 2017).

Inhibitors of sterol biosynthetic enzymes and sphingolipid metabolism and signaling had been proposed as combination partners for Posa (Fügi et al., 2015). Selected inhibitors (Table 1) were phenotypically assessed against T. cruzi. FTY720 and Ro48-
8071 were as active as $\mathrm{Bz}$ against epimastigotes. Against the therapeutically relevant intracellular forms, four compounds had similar or even higher potency than Bz: FTY720, Ro48-8071, tomatidine hydrochloride and TMP-153. The different $\mathrm{EC}_{50}$ values of the studied compounds (including the reference drug) against epimastigotes and amastigotes can be explained by the distinct cellular metabolism of these proliferative forms that face different environments and hosts. Although we cannot exclude variabilities in drug susceptibility among the different strains (Zingales et al., 2014; Zingales, 2018), our data confirm the importance of using the intracellular amastigote form for drug discovery (Romanha et al., 2010; de Castro et al., 2011).

Interestingly, tomatidine hydrochloride $(\mathrm{TH})$ had shown activity against bacteria (Staphylococcus aureus), fungi (Candida albicans), Chikungunya, Dengue, and Zika virus, and the trypanosomatids Phytomonas serpens and Leishmania amazonensis (Mitchell et al., 2011; Mitchell et al., 2012; Robbins et al., 2015; Dorsaz et al., 2017; Soltani et al., 2017; Diosa-Toro et al., 2019; Troost et al., 2020). While ATP synthase was proposed as the target of TH in S. aureus (Lamontagne Boulet et al., 2018), the antifungal and antitrypanosomal target of TH turned out to be C-24 sterol methyltransferase (Medina et al., 2012; Medina et al., 2015; Dorsaz et al., 2017). This enzyme, encoded by the gene ERG6, catalyzes a downstream step of ergosterol synthesis from CYP51 (ERG11). Ro48-8071 targets lanosterol synthase (ERG7), the step immediately before CYP51. In a previous study (PubMed id 9491766, Chataing et al., 1998), tomatidine at $5.7 \mu \mathrm{M}$ inhibited the growth of T. cruzi epimastigote cultures to $50 \%$ after four days of incubation.

Based on their promising activity and selectivity against T. cruzi amastigotes, Ro48-8071 and $\mathrm{TH}$ were selected for in vitro combination testing using fixed-ratio proportions as reported (Simões-Silva et al., 2016). Regarding the choice of partner drugs, $\mathrm{Bz}$ as one of the standard drugs for $\mathrm{CD}$ was an obvious candidate (Coura, 2009). Posa and Fexi are very potent anti-T. cruzi agents in vitro and in vivo (Urbina, 2015) that were moved to clinical trials for CD (Bahia et al., 2012; Morillo et al., 2017; DNDi Portfolio, 2020). None of the combos made with Ro48-8071 showed synergistic activity and were therefore not further investigated. Combos of $\mathrm{Bz}$ and Fexi with $\mathrm{TH}$ were also additive. However, the association of $\mathrm{TH}$ plus Posa was essentially synergistic, displaying $\Sigma \mathrm{FICI}=0.2$.

A synergistic interaction for $\mathrm{TH}$ has already been reported with aminoglycoside antibiotics, being more effective in inhibiting colony growth of $S$. aureus clinical isolates as compared to 

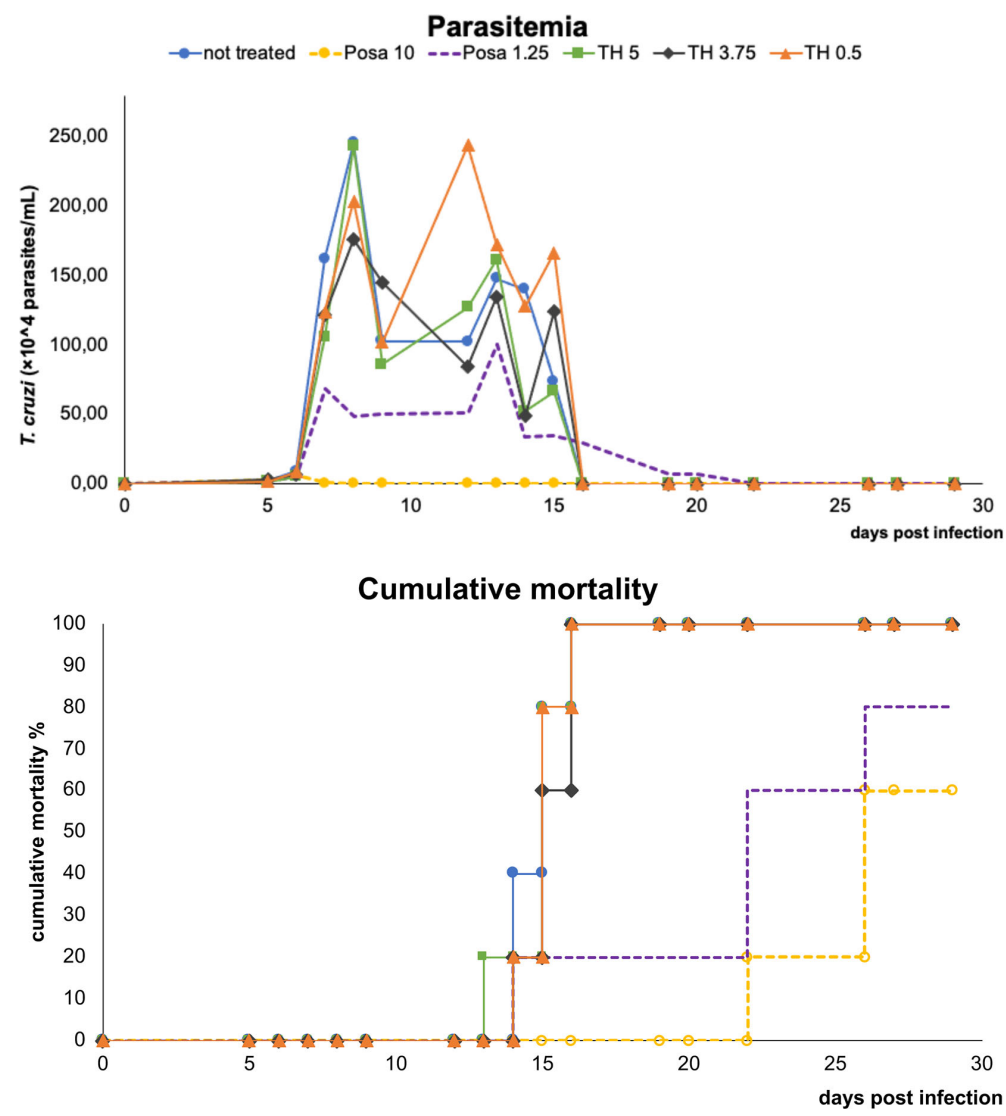

FIGURE 2 | Parasitemia and cumulative mortality of mice infected with T. cruzi (Y strain) treated with vehicle alone, posaconazole (Posa 10 and $1.25 \mathrm{mpk})$, or tomatidine hydrochloride (TH 5, 3.75 and $0.5 \mathrm{mpk}$ ) administrated for ten consecutive days (dpi 5 to 14).

standard monotherapies (Mitchell et al., 2011; Mitchell et al., 2012; Soltani et al., 2017). Also, the combination of TH with fluconazole exhibited synergistic interaction against a $C$. albicans azoleresistant strain (Robbins et al., 2015), thus confirming the potential of $\mathrm{TH}$ for drug combination protocols.

Based on these in vitro results, Posa $+\mathrm{TH}$ was moved to in vivo assays using a well-established mouse model of acute T. cruzi infection (Romanha et al., 2010). TH alone did not present antiparasitic activity in vivo. However, it is important to note that the lack of in vivo efficacy may be due to the poor solubility of TH. Previous studies reported that, as TH is a highly hydrophobic sterol-like molecule, many vehicles including DMSO, ethanol or cyclodextrin failed to demonstrate efficacy in in vivo models of $C$. albicans infection, except for the use of a nanoparticle-based formulation that allowed successful reduction of fungal burden in infected mice (Dorsaz et al., 2017). Thus, the exploration of other formulations for $\mathrm{TH}$ is desirable to better assess its potential against T. cruzi in vivo. When the combos were assayed, the best results in terms of reduction of parasitemia and mortality were obtained with the proportion of Posa $1.25 \mathrm{mpk}+\mathrm{TH} 3.75 \mathrm{mpk}$, which correlates to the most synergistic combo in vitro (drug ratio 1:3). The combination of Posa at $1.25 \mathrm{mpk}$ plus $\mathrm{TH}$ at $3.75 \mathrm{mpk}$ displayed a survival rate of $60 \%$ in the acute infection model as compared to $20 \%$ for Posa at $1.25 \mathrm{mpk}$ alone, and $40 \%$ for Posa at $10 \mathrm{mpk}$ alone.

Thus, our finding that only the combo of Posa plus TH gave a synergistic profile in vitro was further corroborated by our in vivo assays demonstrating a reduction in parasite load and animal death rates. These results possibly are due to the simultaneous action on enzymes (lanosterol 14- $\alpha$ demethylase and sterol 24C-methyltransferase) to the sterol biosynthetic route, impacting the fitness profile and metabolism of the intracellular, clinically relevant form of T. cruzi.

$\mathrm{TH}$ is a natural compound, originally found in unripe tomatoes, that has a wide array of bioactivities including antioxidant, anticarcinogenic and antimicrobial effects (Friedman, 2013). TH exerts antifungal and antitrypanosomatid effects by inhibition of C24 sterol methyltransferase (Medina et al., 2015; Dorsaz et al., 2017). The finding that TH synergistically interacts with Posa encourages further studies with this class of compound and reinforces the potential of drug repurposing and combination protocols. These approaches represent reduced cost and time in the search for better treatments for $\mathrm{CD}$, which is clearly relevant considering the shortage of resources in benefit of the poor population around the world affected by neglected tropical diseases such as Chagas disease. Although Posa at $10 \mathrm{mpk}$ and the combo Posa $1.25 \mathrm{mpk}+$ 

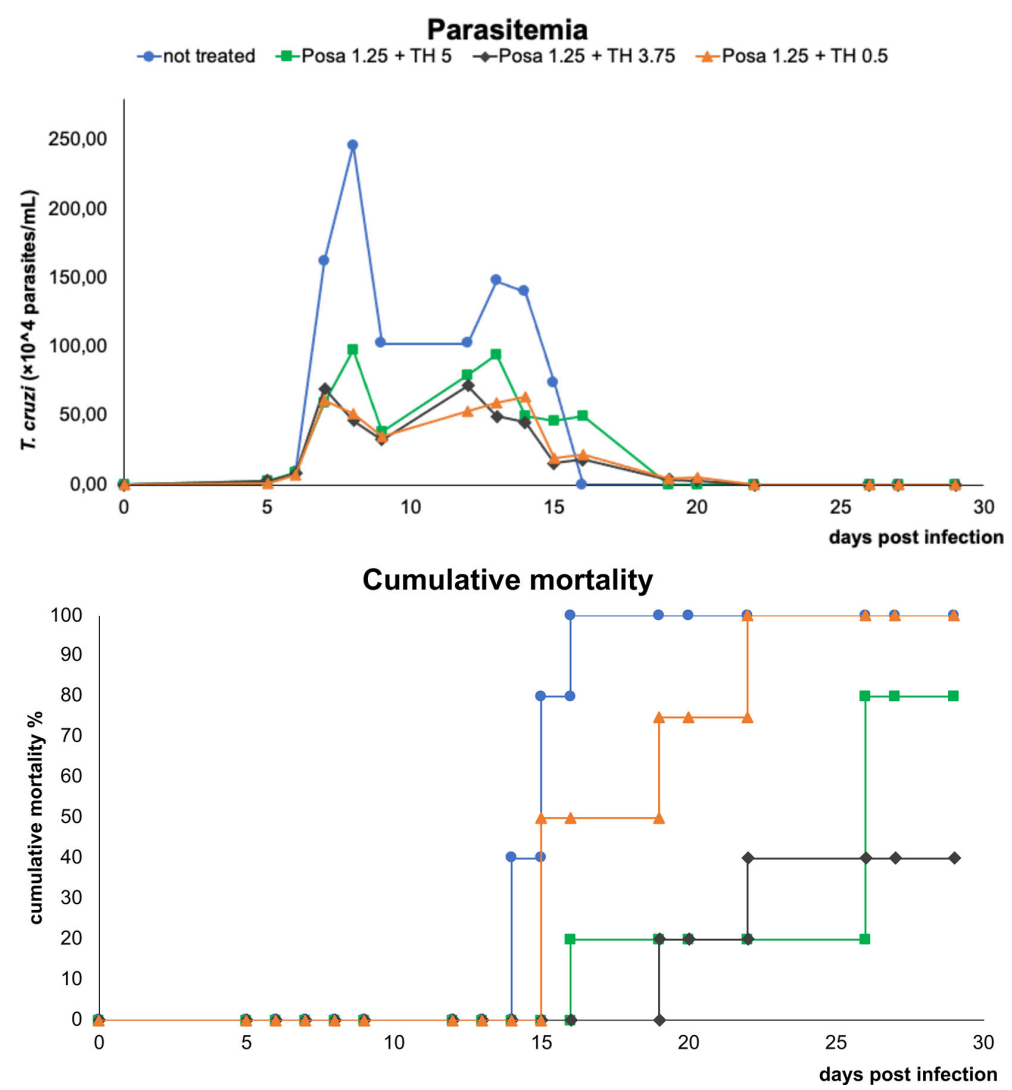

FIGURE 3 | Parasitemia and cumulative mortality of mice infected with T. cruzi (Y strain) treated with vehicle or different co-administration proportions of posaconazole and tomatidine hydrochloride (Posa $1.25+\mathrm{TH} 5$, Posa $1.25+$ TH 3.75 and Posa $1.25+$ TH 0.5 mpk) for ten consecutive days (dpi 5 to 14 ).

TH $3.75 \mathrm{mpk}$ suppressed/highly reduced the parasitemia, neither therapeutic scheme was able to reach $100 \%$ animal survival and induce sterile cure. Thus, further studies will need to address the efficacy against dormant forms of T. cruzi as recent data suggest the existence of an adaptive difference between parasite strains to generate dormant cells, and that homologous recombination in $T$. cruzi may be important for dormancy stages (Sánchez-Valdéz and Padilla, 2019; Resende et al., 2020).

\section{DATA AVAILABILITY STATEMENT}

The raw data supporting the conclusions of this article will be made available by the authors, without undue reservation.

\section{ETHICS STATEMENT}

All procedures followed the guidelines in compliance with the Fiocruz Committee of Ethics for the Use of Animals (CEUA L-38/17).

\section{AUTHOR CONTRIBUTIONS}

MR-H performed the in vitro and in vivo studies, data analysis, and drafted the manuscript. PM, MK, and MS (corresponding author) obtained the funding, conceived the study, performed data analysis, and drafted the manuscript. XG helped in drafting the manuscript and in study design. GO, AD, LF, and RP contributed to the in vivo studies. AF, MC, and RR contributed to the in vitro studies. All authors contributed to the article and approved the submitted version.

\section{FUNDING}

The fundings were provided by the Swiss National Science Foundation (SNF grant IZRJZ3_164172), Fundação Carlos Chagas Filho de Amparo à Pesquisa do Rio de Janeiro (FAPERJ), Coordenação de Aperfeiçoamento de Pessoal de Nível Superior (CAPES), Conselho Nacional de Desenvolvimento Científico e Tecnológico (CNPQ), PAEF, and Instituto Oswaldo Cruz (IOC/ Fiocruz). MS is CNPq fellow and Cientista do Nosso Estado CNE FAPERJ.

\section{ACKNOWLEDGMENTS}

We would like to thank the opportunity of taking part in the Brazilian-Swiss Joint Research Programme (BSJRP) funded by CNPq, FAPERJ, CAPES, and SNF. We also thank Ivana Melo, Dr Kelly Cristina Demarque, and Patrícia Bernardino da Silva for technical support. 


\section{REFERENCES}

Alves, F., Bilbe, G., Blesson, S., Goyal, V., Monnerat, S., Mowbray, C., et al. (2018). Recent Development of Visceral Leishmaniasis Treatments: Successes, Pitfalls, and Perspectives. Clin. Microbiol. Rev. 31 (4), e00048-e00018. doi: 10.1128/ CMR.00048-18

Atia, A. M., Mumina, A., Tayler-Smith, K., Boulle, P., Alcoba, G., Elhag, M. S., et al. (2015). Sodium stibogluconate and paromomycin for treating visceral leishmaniasis under routine conditions in eastern Sudan. Trop. Med. Int. Health 20 (12), 1674-1684. doi: 10.1111/tmi.12603

Bahia, M. T., de Andrade, I. M., Martins, T. A., do Nascimento, Á. F., Diniz Lde, F., Caldas, I. S., et al. (2012). Fexinidazole: a potential new drug candidate for Chagas disease. PloS Negl. Trop. Dis. 6 (11), e1870. doi: 10.1371/ journal.pntd.0001870

Batista, D. G., Batista, M. M., de Oliveira, G. M., Britto, C. C., Rodrigues, A. C., Stephens, C. E., et al. (2011). Combined treatment of heterocyclic analogues and benznidazole upon Trypanosoma cruzi in vivo. PloS One 6 (7), e22155. doi: 10.1371/journal.pone.0022155

Brener, Z. (1962). Therapeutic activity and criterion of cure on mice experimentally infected with Trypanosoma cruzi. Rev. Inst. Med. Trop. Sao Paulo 4, 389-396.

Buckner, F. S., Verlinde, C. L., La Flamme, A. C., and Van Voorhis, W. C. (1996). Efficient technique for screening drugs for activity against Trypanosoma cruzi using parasites expressing beta-galactosidase. Antimicrob. Agents Chemother. 40 (11), 2592-2597. doi: 10.1128/AAC.40.11.2592

Cal, M., Ioset, J. R., Fügi, M. A., Mäser, P., and Kaiser, M. (2016). Assessing anti-T. cruzi candidates in vitro for sterile cidality. Int. J. Parasitol. Drugs Drug Resist. 6 (3), 165-170. doi: 10.1016/j.ijpddr.2016.08.003

Chagas, C. (1909). Nova tripanozomiase humana: estudos sobre a morfolojia e o ciclo evolutivo do Schizotrypanum cruzi n. gen., n. sp., ajente etiolojico de nova entidade morbida do homem. Mem. Inst. Oswaldo Cruz Rio Janeiro 1 (2), 159218.

Chataing, B., Concepción, J. L., Lobatón, R., and Usubillaga, A. (1998). Inhibition of Trypanosoma cruzi growth in vitro by Solanum alkaloids: a comparison with ketoconazole. Planta Med 64 (1), 31-36. doi: 10.1055/s-2006-957361

Chatelain, E., and Ioset, J. R. (2018). Phenotypic screening approaches for Chagas disease drug discovery. Expert Opin. Drug Discov. 13 (2), 141-153. doi: 10.1080/17460441.2018.1417380

Coura, J. R., Viñas, P. A., and Junqueira, A. C. (2014). Ecoepidemiology, short history and control of Chagas disease in the endemic countries and the new challenge for non-endemic countries. Mem. Inst. Oswaldo Cruz 109 (7), 856862. doi: 10.1590/0074-0276140236

Coura, J. R. (2009). Present situation and new strategies for Chagas disease chemotherapy: a proposal. Mem. Inst. Oswaldo Cruz 104 (4), 549-554. doi: 10.1590/s0074-02762009000400002

de Castro, S. L., Batista, D. G., Batista, M. M., Batista, W., Daliry, A., de Souza, E. M., et al. (2011). Experimental Chemotherapy for Chagas Disease: A Morphological, Biochemical, and Proteomic Overview of Potential Trypanosoma cruzi Targets of Amidines Derivatives and Naphthoquinones. Mol. Biol. Int. 2011:306928. doi: 10.4061/2011/306928

Dias, J. C. P. (2017). Facing Chagas disease. Rev. Soc. Bras. Med. Trop. 50 (3), 285286. doi: 10.1590/0037-8682-0254-2017

Diniz, L. F., Urbina, J. A., de Andrade, I. M., Mazzeti, A. L., Martins, T. A., Caldas, I. S., et al. (2013). Benznidazole and posaconazole in experimental Chagas disease: positive interaction in concomitant and sequential treatments. PloS Negl. Trop. Dis. 7 (8), e2367. doi: 10.1371/journal.pntd.0002367

Diosa-Toro, M., Troost, B., van de Pol, D., Heberle, A. M., Urcuqui-Inchima, S., Thedieck, K., et al. (2019). Tomatidine, a novel antiviral compound towards dengue virus. Antiviral Res. 161, 90-99. doi: 10.1016/j.antiviral.2018.11.011

Dorsaz, S., Snäkä, T., Favre-Godal, Q., Maudens, P., Boulens, N., Furrer, P., et al. (2017). Identification and Mode of Action of a Plant Natural Product Targeting Human Fungal Pathogens. Antimicrob. Agents Chemother. 61 (9), e00829e00817. doi: 10.1128/AAC.00829-17

Drugs for Neglected Disease initiative (2020). DNDi Portfolio. Available at: https:// www.dndi.org/diseases-projects/portfolio/; dndi.org/research-development/ portfolio/ (Acessed June 10, 2020)

Eisenkolb, M., Zenzmaier, C., Leitner, E., and Schneiter, R. (2002). A specific structural requirement for ergosterol in long-chain fatty acid synthesis mutants important for maintaining raft domains in yeast. Mol. Biol. Cell. 13 (12), 4414 4428. doi: 10.1091/mbc.e02-02-0116

Fesser, A. F., Braissant, O., Olmo, F., Kelly, J. M., Mäser, P., and Kaiser, M. (2020). Non-invasive monitoring of drug action: A new live in vitro assay design for Chagas' disease drug discovery. PloS Negl. Trop. Dis. 14 (7), e0008487. doi: 10.1371/journal.pntd.0008487

Fivelman, Q. L., Adagu, I. S., and Warhurst, D. C. (2004). Modified fixed-ratio isobologram method for studying in vitro interactions between atovaquone and proguanil or dihydroartemisinin against drug-resistant strains of Plasmodium falciparum. Antimicrob. Agents Chemother. 48 (11), 4097-4102. doi: 10.1128/AAC.48.11.4097-4102.2004

Francisco, A. F., Lewis, M. D., Jayawardhana, S., Taylor, M. C., Chatelain, E., and Kelly, J. M. (2015). Limited Ability of Posaconazole To Cure both Acute and Chronic Trypanosoma cruzi Infections Revealed by Highly Sensitive In Vivo Imaging. Antimicrob. Agents Chemother. 59 (8), 4653-4661. doi: 10.1128/ AAC.00520-15

Friedman, M. (2013). Anticarcinogenic, cardioprotective, and other health benefits of tomato compounds lycopene, $\alpha$-tomatine, and tomatidine in pure form and in fresh and processed tomatoes. J. Agric. Food Chem. 61 (40), 9534-9550. doi: 10.1021/jf402654e

Fügi, M. A., Kaiser, M., Tanner, M., Schneiter, R., Mäser, P., and Guan, X. L. (2015). Match-making for posaconazole through systems thinking. Trends Parasitol. 31 (2), 46-51. doi: 10.1016/j.pt.2014.11.004

Gascon, J., Bern, C., and Pinazo, M. J. (2010). Chagas disease in Spain, the United States and other non-endemic countries. Acta Trop. 115 (1-2), 22-27. doi: 10.1016/j.actatropica.2009.07.019

Goldston, A. M., Powell, R. R., and Temesvari, L. A. (2012). Sink or swim: lipid rafts in parasite pathogenesis. Trends Parasitol. 28 (10), 417-426. doi: 10.1016/ j.pt.2012.07.002

Guan, X. L., and Mäser, P. (2017). Comparative sphingolipidomics of diseasecausing trypanosomatids reveal unique lifecycle- and taxonomy-specific lipid chemistries. Sci. Rep. 7 (1), 13617. doi: 10.1038/s41598-017-13931-x

Guan, X. L., Souza, C. M., Pichler, H., Dewhurst, G., Schaad, O., Kajiwara, K., et al. (2009). Functional interactions between sphingolipids and sterols in biological membranes regulating cell physiology. Mol. Biol. Cell. 20 (7), 2083-2095. doi: 10.1091/mbc.e08-11-1126

Guedes-da-Silva, F. H., Batista, D. G., da Silva, C. F., Meuser, M. B., Simões-Silva, M. R., de Araújo, J. S., et al. (2015). Different Therapeutic Outcomes of Benznidazole and VNI Treatments in Different Genders in Mouse Experimental Models of Trypanosoma cruzi Infection. Antimicrob. Agents Chemother. 59 (12), 7564-7570. doi: 10.1128/AAC.01294-15

Kim, S., Chen, J., Cheng, T., Gindulyte, A., He, J., He, S., et al. (2021). PubChem in 2021: new data content and improved web interfaces. Nucleic Acids Res. 49 (D1), D1388-D1395. doi: 10.1093/nar/gkaa971

Lamontagne Boulet, M., Isabelle, C., Guay, I., Brouillette, E., Langlois, J. P., Jacques, P. É., et al. (2018). Tomatidine Is a Lead Antibiotic Molecule That Targets Staphylococcus aureus ATP Synthase Subunit C. Antimicrob. Agents Chemother. 62 (6), e02197-e02117. doi: 10.1128/AAC.02197-17

Malik, L. H., Singh, G. D., and Amsterdam, E. A. (2015). Chagas Heart Disease: An Update. Am. J. Med. 128 (11), 1251.e7-9. doi: 10.1016/j.amjmed.2015. 04.036

Medina, J. M., Rodrigues, J. C., De Souza, W., Atella, G. C., and Barrabin, H. (2012). Tomatidine promotes the inhibition of 24-alkylated sterol biosynthesis and mitochondrial dysfunction in Leishmania amazonensis promastigotes. Parasitology 139 (10), 1253-1265. doi: 10.1017/S0031182012000522

Medina, J. M., Rodrigues, J. C., Moreira, O. C., Atella, G., Souza, W. D., and Barrabin, H. (2015). Mechanisms of growth inhibition of Phytomonas serpens by the alkaloids tomatine and tomatidine. Mem. Inst. Oswaldo Cruz 110 (1), 48-55. doi: 10.1590/0074-02760140097

Meirelles, M. N., de Araujo-Jorge, T. C., Miranda, C. F., de Souza, W., and Barbosa, H. S. (1986). Interaction of Trypanosoma cruzi with heart muscle cells: ultrastructural and cytochemical analysis of endocytic vacuole formation and effect upon myogenesis in vitro. Eur. J. Cell Biol. 41 (2), 198-206.

Miranda, M. R., and Sayé, M. M. (2019). Chagas Disease Treatment: From New Therapeutic Targets to Drug Discovery and Repositioning. Curr. Med. Chem. 26 (36), 6517-6518. doi: 10.2174/092986732636191202125919

Mitchell, G., Gattuso, M., Grondin, G., Marsault, É., Bouarab, K., and Malouin, F. (2011). Tomatidine inhibits replication of Staphylococcus aureus small-colony 
variants in cystic fibrosis airway epithelial cells. Antimicrob. Agents Chemother. 55 (5), 1937-1945. doi: 10.1128/AAC.01468-10

Mitchell, G., Lafrance, M., Boulanger, S., Séguin, D. L., Guay, I., Gattuso, M., et al. (2012). Tomatidine acts in synergy with aminoglycoside antibiotics against multiresistant Staphylococcus aureus and prevents virulence gene expression. J. Antimicrob. Chemother. 67 (3), 559-568. doi: 10.1093/jac/dkr510

Molina, I., Salvador, F., Sánchez-Montalvá, A., Treviño, B., Serre, N., Sao Avilés, A., et al. (2015). Toxic Profile of Benznidazole in Patients with Chronic Chagas Disease: Risk Factors and Comparison of the Product from Two Different Manufacturers. Antimicrob. Agents Chemother. 59 (10), 6125-6131. doi: 10.1128/AAC.04660-14

Moraes, C. B., Giardini, M. A., Kim, H., Franco, C. H., Araujo-Junior, A. M., Schenkman, S., et al. (2014). Nitroheterocyclic compounds are more efficacious than CYP51 inhibitors against Trypanosoma cruzi: implications for Chagas disease drug discovery and development. Sci. Rep. 4, 4703. doi: 10.1038/ srep04703

Morillo, C. A., Waskin, H., Sosa-Estani, S., Del Carmen Bangher, M., Cuneo, C., Milesi, R., et al. (2017). STOP-CHAGAS Investigators. Benznidazole and Posaconazole in Eliminating Parasites in Asymptomatic T. cruzi Carriers: The STOP-CHAGAS Trial. J. Am. Coll. Cardiol. 69 (8), 939-947. doi: 10.1016/ j.jacc.2016.12.023

Odds, F. C. (2003). Synergy, antagonism, and what the chequerboard puts between them. J. Antimicrob. Chemother. 52 (1):1. doi: 10.1093/jac/dkg301

Pérez-Molina, J. A., and Molina, I. (2018). Chagas disease. Lancet 391 (10115), 8294. doi: $10.1016 / \mathrm{S} 0140-6736(17) 31612-4$

Prata, A. (2001). Clinical and epidemiological aspects of Chagas disease. Lancet Infect. Dis. 1 (2), 92-100. doi: 10.1016/S1473-3099(01)00065-2

Priotto, G., Kasparian, S., Ngouama, D., Ghorashian, S., Arnold, U., Ghabri, S., et al. (2007). Nifurtimox-eflornithine combination therapy for second-stage Trypanosoma brucei gambiense sleeping sickness: a randomized clinical trial in Congo. Clin. Infect. Dis. 45 (11), 1435-1442. doi: 10.1086/522982

Pruett, S. T., Bushnev, A., Hagedorn, K., Adiga, M., Haynes, C. A., Sullards, M. C., et al. (2008). Biodiversity of sphingoid bases ("sphingosines") and related amino alcohols. J. Lipid Res. 49 (8), 1621-1639. doi: 10.1194/jlr.R800012-JLR200

Rahman, R., Goyal, V., Haque, R., Jamil, K., Faiz, A., Samad, R., et al. (2017). Safety and efficacy of short course combination regimens with AmBisome, miltefosine and paromomycin for the treatment of visceral leishmaniasis (VL) in Bangladesh. PloS Negl. Trop. Dis. 11 (5), e0005635. doi: 10.1371/ journal.pntd.0005635

Rassi, A., Rassi, A., and Marin-Neto, J. A. (2010). Chagas disease. Lancet 375 (9723), 1388-1402. doi: 10.1016/S0140-6736(10)60061-X

Rassi, A., Marin, J. A. N., and Rassi, A. (2017). Chronic Chagas cardiomyopathy: a review of the main pathogenic mechanisms and the efficacy of aetiological treatment following the BENznidazole Evaluation for Interrupting Trypanosomiasis (BENEFIT) trial. Mem. Inst. Oswaldo Cruz 112 (3), 224235. doi: 10.1590/0074-02760160334

Räz, B., Iten, M., Grether-Bühler, Y., Kaminsky, R., and Brun, R. (1997). The Alamar Blue assay to determine drug sensitivity of African trypanosomes (T.b. rhodesiense and T.b. gambiense) in vitro. Acta Trop. 68 (2), 139-147. doi: 10.1016/s0001-706x(97)00079-x

Resende, B. C., Oliveira, A. C. S., Guañabens, A. C. P., Repolês, B. M., Santana, V., Hiraiwa, P. M., et al. (2020). The Influence of Recombinational Processes to Induce Dormancy in Trypanosoma cruzi. Front. Cell Infect. Microbiol. 10, 5. doi: $10.3389 /$ fcimb.2020.00005

Ribeiro, A. L., Nunes, M. P., Teixeira, M. M., and Rocha, M. O. (2012). Diagnosis and management of Chagas disease and cardiomyopathy. Nat. Rev. Cardiol. 9 (10), 576-589. doi: 10.1038/nrcardio.2012.109

Robbins, N., Spitzer, M., Yu, T., Cerone, R. P., Averette, A. K., Bahn, Y. S., et al. (2015). An Antifungal Combination Matrix Identifies a Rich Pool of Adjuvant Molecules that Enhance Drug Activity against Diverse Fungal Pathogens. Cell Rep. 13 (7), 1481-1492. doi: 10.1016/j.celrep.2015.10.018

Romanha, A. J., Castro, S. L., Soeiro Mde, N., Lannes-Vieira, J., Ribeiro, I., Talvani, A., et al. (2010). In vitro and in vivo experimental models for drug screening and development for Chagas disease. Mem. Inst. Oswaldo Cruz 105 (2), 233238. doi: $10.1590 / \mathrm{s} 0074-02762010000200022$
Sales Junior, P. A., Molina, I., Fonseca Murta, S. M., Sánchez-Montalvá, A., Salvador, F., Corrêa-Oliveira, R., et al. (2017). Experimental and Clinical Treatment of Chagas Disease: A Review. Am. J. Trop. Med. Hyg. 97 (5), 1289-1303. doi: 10.4269/ajtmh.16-0761

Sánchez-Valdéz, F., and Padilla, A. (2019). In Situ Detection of Dormant Trypanosoma cruzi Amastigotes Using Bioluminescent-Fluorescent Reporters. Methods Mol. Biol. 1955, 179-186. doi: 10.1007/978-1-4939-91488_13

Sbaraglini, M. L., Vanrell, M. C., Bellera, C. L., Benaim, G., Carrillo, C., Talevi, A., et al. (2016). Neglected Tropical Protozoan Diseases: Drug Repositioning as a Rational Option. Curr. Top. Med. Chem. 16 (19), 2201-2222. doi: 10.2174/ 1568026616666160216154309

Simões-Silva, M. R., Nefertiti, A. S., De Araújo, J. S., Batista, M. M., Da Silva, P. B., Bahia, M. T., et al. (2016). Phenotypic Screening In Vitro of Novel Aromatic Amidines against Trypanosoma cruzi. Antimicrob. Agents Chemother. 60 (8), 4701-4707. doi: 10.1128/AAC.01788-15

Simões-Silva, M. R., De Araújo, J. S., Oliveira, G. M., Demarque, K. C., Peres, R. B., D’Almeida-Melo, I., et al. (2017). Drug repurposing strategy against Trypanosoma cruzi infection: In vitro and in vivo assessment of the activity of metronidazole in mono- and combined therapy. Biochem. Pharmacol. 145, 46-53. doi: 10.1016/j.bcp.2017.08.025

Soltani, R., Fazeli, H., Bahri Najafi, R., and Jelokhanian, A. (2017). Evaluation of the Synergistic Effect of Tomatidine with Several Antibiotics against Standard and Clinical Isolates of Staphylococcus aureus, Enterococcus faecalis, Pseudomonas aeruginosa and Escherichia coli. Iran J. Pharm. Res. 16 (1), 290-296.

Sun, W., Sanderson, P. E., and Zheng, W. (2016). Drug combination therapy increases successful drug repositioning. Drug Discov. Today 21 (7), 1189-1195. doi: 10.1016/j.drudis.2016.05.015

Torrico, F., Gascon, J., Ortiz, L., Alonso-Vega, C., Pinazo, M. J., Schijman, A., et al. (2018). Treatment of adult chronic indeterminate Chagas disease with benznidazole and three E1224 dosing regimens: a proof-of-concept, randomised, placebo-controlled trial. Lancet Infect. Dis. 18 (4), 419-430. doi: 10.1016/S1473-3099(17)30538-8

Troost, B., Mulder, L. M., Diosa-Toro, M., van de Pol, D., Rodenhuis-Zybert, I. A., and Smit, J. M. (2020). Tomatidine, a natural steroidal alkaloid shows antiviral activity towards chikungunya virus in vitro. Sci. Rep. 10 (1), 6364. doi: 10.1038/ s41598-020-63397-7

Urbina, J. A. (2015). Recent clinical trials for the etiological treatment of chronic chagas disease: advances, challenges and perspectives. J. Eukaryot. Microbiol. 62 (1), 149-156. doi: 10.1111/jeu.12184

Urbina, J. A. (2018). The long road towards a safe and effective treatment of chronic Chagas disease. Lancet Infect. Dis. 18 (4), 363-365. doi: 10.1016/S14733099(17)30535-2

Zingales, B., Miles, M. A., Moraes, C. B., Luquetti, A., Guhl, F., Schijman, A. G., et al. (2014). Drug discovery for Chagas disease should consider Trypanosoma cruzi strain diversity. Mem. Inst. Oswaldo Cruz 109 (6), 828-833. doi: 10.1590/ 0074-0276140156

Zingales, B. (2018). Trypanosoma cruzi genetic diversity: Something new for something known about Chagas disease manifestations, serodiagnosis and drug sensitivity. Acta Trop. 184, 38-52. doi: 10.1016/j.actatropica. 2017.09.017

Conflict of Interest: The authors declare that the research was conducted in the absence of any commercial or financial relationships that could be construed as a potential conflict of interest.

Copyright (ङ 2021 Rocha-Hasler, de Oliveira, da Gama, Fiuza, Fesser, Cal, Rocchetti, Peres, Guan, Kaiser, Soeiro and Mäser. This is an open-access article distributed under the terms of the Creative Commons Attribution License (CC BY). The use, distribution or reproduction in other forums is permitted, provided the original author (s) and the copyright owner(s) are credited and that the original publication in this journal is cited, in accordance with accepted academic practice. No use, distribution or reproduction is permitted which does not comply with these terms. 